Supporting Information:

\title{
Simultaneous Measurement of Striatal Dopamine and Hydrogen Peroxide Transients Associated with L-DOPA Induced Rotation in Hemiparkinsonian Rats
}

Leslie R. Wilson ${ }^{1, \#}$, Christie A. Lee ${ }^{1, \#}$, Catherine F. Mason ${ }^{1}$, Sitora Khodjaniyazova1, Kevin Flores ${ }^{2}$, David C. Muddiman ${ }^{1,3,4}$, and ${ }^{*}$ Leslie A. Sombers ${ }^{1,4}$

${ }^{1}$ Department of Chemistry, ${ }^{2}$ Department of Mathematics, ${ }^{3}$ Molecular Education, Technology, and Research Innovation Center (METRIC), and ${ }^{4}$ Comparative Medicine Institute, North Carolina State University, Raleigh, North Carolina 27695, United States \#These authors contributed equally 
a.

\section{A.I.M.s}
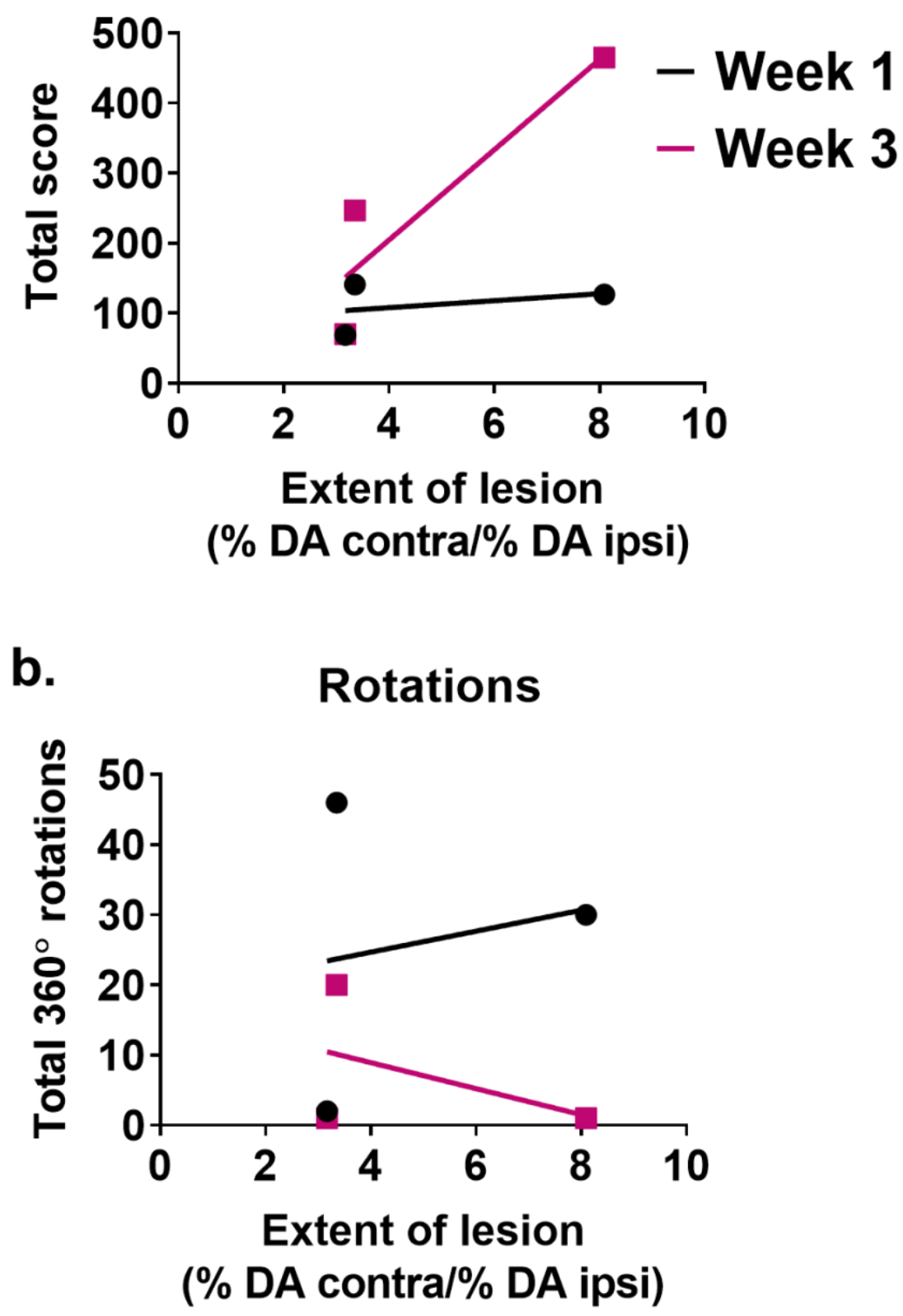

Figure S1: A linear regression relating the extent of the 6-OHDA lesion to L-DOPA induced dyskinetic movements. (a.) The total A.I.M.s score correlates with the extent of the lesion after 3 weeks $\left(R^{2}=0.825\right)$, but not 1 week $\left(R^{2}=0.223\right)$ of L-DOPA treatment. (b.) The total number of $360^{\circ}$ rotations performed by lesioned rats during the $185-\mathrm{min}$ evaluation period does not correlate with the extent of the lesion in week $1\left(R^{2}=0.035\right)$ or week $3\left(R^{2}=0.223\right)$. 


\begin{tabular}{|c|c|c|c|c|c|c|c|c|}
\hline & Treatment & Week & Time & Time $\times$ Week & $\begin{array}{c}\text { Time } x \\
\text { Treatment }\end{array}$ & $\begin{array}{l}\text { Week x } \\
\text { Treatment }\end{array}$ & $\begin{array}{c}\text { Time } \mathrm{x} \text { Week } \mathrm{x} \\
\text { Treatment }\end{array}$ \\
\hline \multicolumn{9}{|c|}{ Dyskinetic Behavior Analysis of Lesioned L-DOPA vs Pooled Controls (Treatment $x$ Week x Time) } \\
\hline \multicolumn{2}{|c|}{$\begin{array}{l}\text { A.I.M.s (axial, } \\
\text { orolingual, limb) }\end{array}$} & $\begin{array}{c}F_{1,15}=4.984, \\
P=0.0413\end{array}$ & $\begin{array}{c}F_{1,15}=70.77, \\
P<0.0001\end{array}$ & $\begin{array}{c}F_{9,135}=22.03, \\
P<0.0001\end{array}$ & $\begin{array}{c}F_{9,135}=22.03 \\
P<0.0001\end{array}$ & $\begin{array}{c}F_{9,135}=3.175, \\
P=0.0016\end{array}$ & $\begin{array}{c}F_{1,15}=4.984, \\
P=0.0413\end{array}$ & $\begin{array}{c}F_{9,135}=3.175 \\
P=0.0016\end{array}$ \\
\hline \multicolumn{2}{|c|}{$360^{\circ}$ Rotations } & $\begin{array}{c}F_{1,15}=0.4824, \\
P=0.4979\end{array}$ & $\begin{array}{c}F_{1,15}=11.29, \\
P=0.0043\end{array}$ & $\begin{array}{c}F_{9,135}=8.513 \\
P<0.0001\end{array}$ & $\begin{array}{c}F_{9,135}=8.513 \\
P<0.0001\end{array}$ & $\begin{array}{c}F_{9,135}=1.953, \\
P=0.0496\end{array}$ & $\begin{array}{c}F_{1,15}=0.4824, \\
P=0.4979\end{array}$ & $\begin{array}{c}F_{9,135}=1.953 \\
P=0.0496\end{array}$ \\
\hline & & Treatment & p-value & Time & p-value & Interaction(s) & p-value & \\
\hline \multicolumn{8}{|c|}{$\begin{array}{c}\text { p-value } \\
\text { Tone Analysis Week } 1\end{array}$} & \\
\hline \multirow{2}{*}{ Ipsilateral } & DA & $F_{3,78}=11.34$ & $P=<0.0001$ & $F_{9,78}=0.30$ & $P=0.9724$ & $F_{27,78}=0.39$ & $P=0.9965$ & \\
\hline & $\mathrm{H}_{2} \mathrm{O}_{2}$ & $F_{3,77}=10.43$ & $P=<0.0001$ & $F_{9,77}=0.1513$ & $P=0.9978$ & $F_{27,77}=0.3961$ & $P=0.9958$ & \\
\hline \multirow[t]{2}{*}{ Contralateral } & DA & $F_{3,56}=0.84$ & $P=0.4785$ & $F_{9,56}=0.8243$ & $P=0.5965$ & $F_{27,56}=0.3956$ & $P=0.9949$ & \\
\hline & $\mathrm{H}_{2} \mathrm{O}_{2}$ & $F_{3,56}=4.514$ & $P=0.0066$ & $F_{9,56}=0.1998$ & $P=0.9932$ & $F_{27,56}=0.3629$ & $P=0.9974$ & \\
\hline \multicolumn{9}{|c|}{ Tone Analysis Week 3} \\
\hline \multirow{2}{*}{ Ipsilateral } & DA & $F_{3,66}=4.776$ & $P=0.0045$ & $F_{9,66}=0.5159$ & $P=0.8580$ & $F_{27,66}=0.5270$ & $P=0.9664$ & \\
\hline & $\mathrm{H}_{2} \mathrm{O}_{2}$ & $F_{3,70}=2.447$ & $P=0.0409$ & $F_{9,70}=0.1038$ & $P=0.9995$ & $F_{27,70}=0.3441$ & $P=0.9985$ & \\
\hline \multirow{2}{*}{ Contralateral } & DA & $F_{3,67}=4.678$ & $P=0.0050$ & $F_{9,67}=1.234$ & $P=0.2896$ & $F_{27,67}=0.6242$ & $P=0.9124$ & \\
\hline & $\mathrm{H}_{2} \mathrm{O}_{2}$ & $F_{3,67}=6.003$ & $P=0.0011$ & $F_{9,67}=1.138$ & $P=0.3490$ & $\mathrm{~F}_{27,67}=1.269$ & $P=0.2143$ & \\
\hline
\end{tabular}

Table S1: Quantitative summary of data depicted in Figure 2 (dyskinetic behavior, threeway ANOVA) and in Figure 3 (neurochemical tone, two-way ANOVAs) with significant main effects and interactions in bold text. 

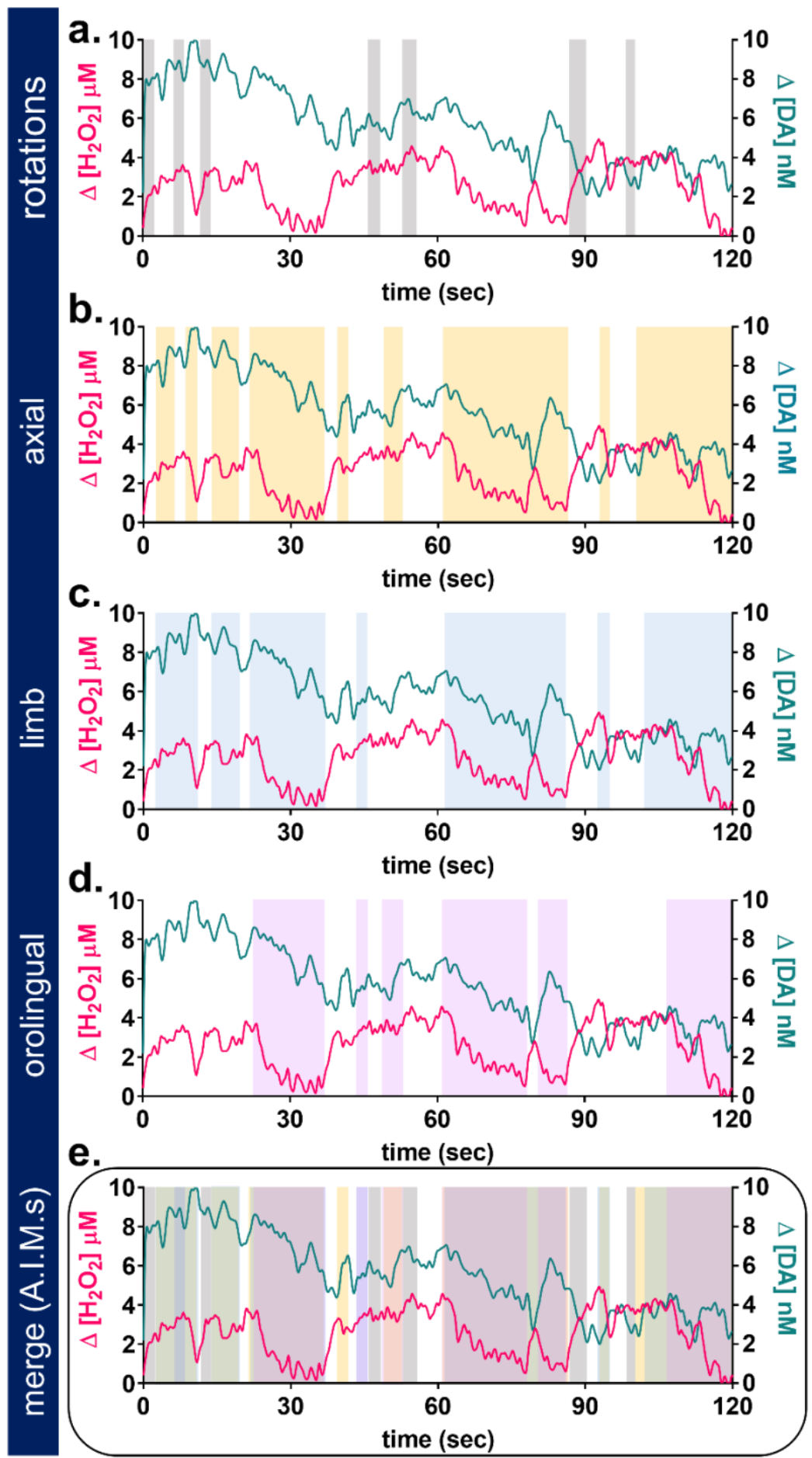

Figure S2: Representative DA and $\mathrm{H}_{2} \mathrm{O}_{2}$ dynamics time locked to rotations (a) and A.I.M.s (b-d) in a 6-OHDA lesioned rat after 3 weeks of chronic L-DOPA treatment. An inverse correlation between $\mathrm{H}_{2} \mathrm{O}_{2}$ and DA was observed with onset of rotation (a). However, chemical dynamics were not correlated with axial (b), limb (c), or orolingual (d) A.I.M.s. A panel aligning chemical dynamics with all of the abnormal movements is also shown (e). 
35-40 mins

a.

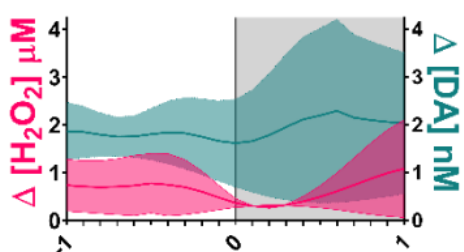

d.

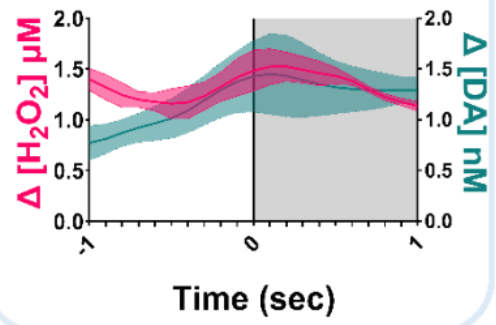

$\sim 55-60$ mins

b.

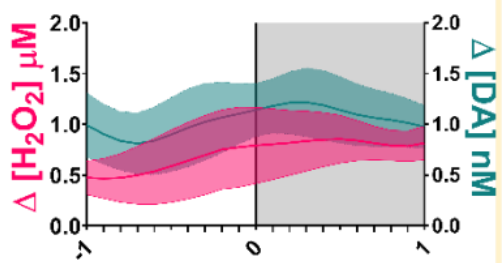

e.

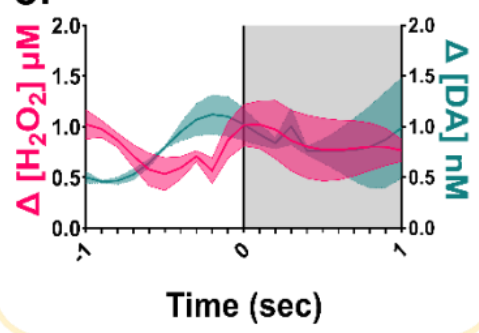

$\sim 85-90$ mins
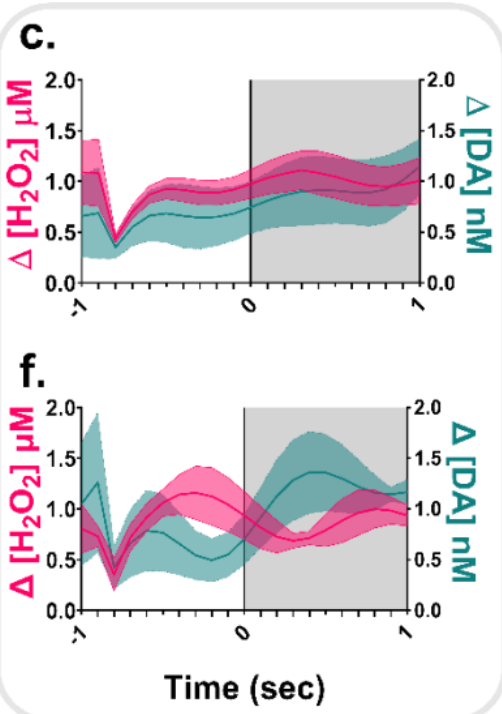

Figure S3: After 1 week of L-DOPA, DA and $\mathrm{H}_{2} \mathrm{O}_{2}$ transients did not reliably correlate with L-DOPA induced contraversive rotation. A detailed analysis correlating DA (teal) with $\mathrm{H}_{2} \mathrm{O}_{2}$ (pink) transients around the onset of L-DOPA induced rotational behavior (periods of rotational behavior are shaded in gray). In ipsilateral striata $(n=2-3)$, DA and $\mathrm{H}_{2} \mathrm{O}_{2}$ concentrations positively correlated with one another around the onset of rotation $(\mathbf{c}, \mathbf{b}: \mathbf{\rho}$ $=0.5909-0.81, P=0.0048$ and $P<0.0001$, respectively), with the exception of the first time point $(\mathbf{a} ; \rho=0.3597, P=0.1092)$. In the contralateral striata $(n=2-3)$, a similar positive correlation was found at the first time point $(\mathbf{d}: \rho=0.69, P=0.0006)$; however, this was not apparent in subsequent recording epochs (e,f: $\rho=-0.161-0.4065, P=0.4856$ and $P$ $=0.0675$, respectively). 

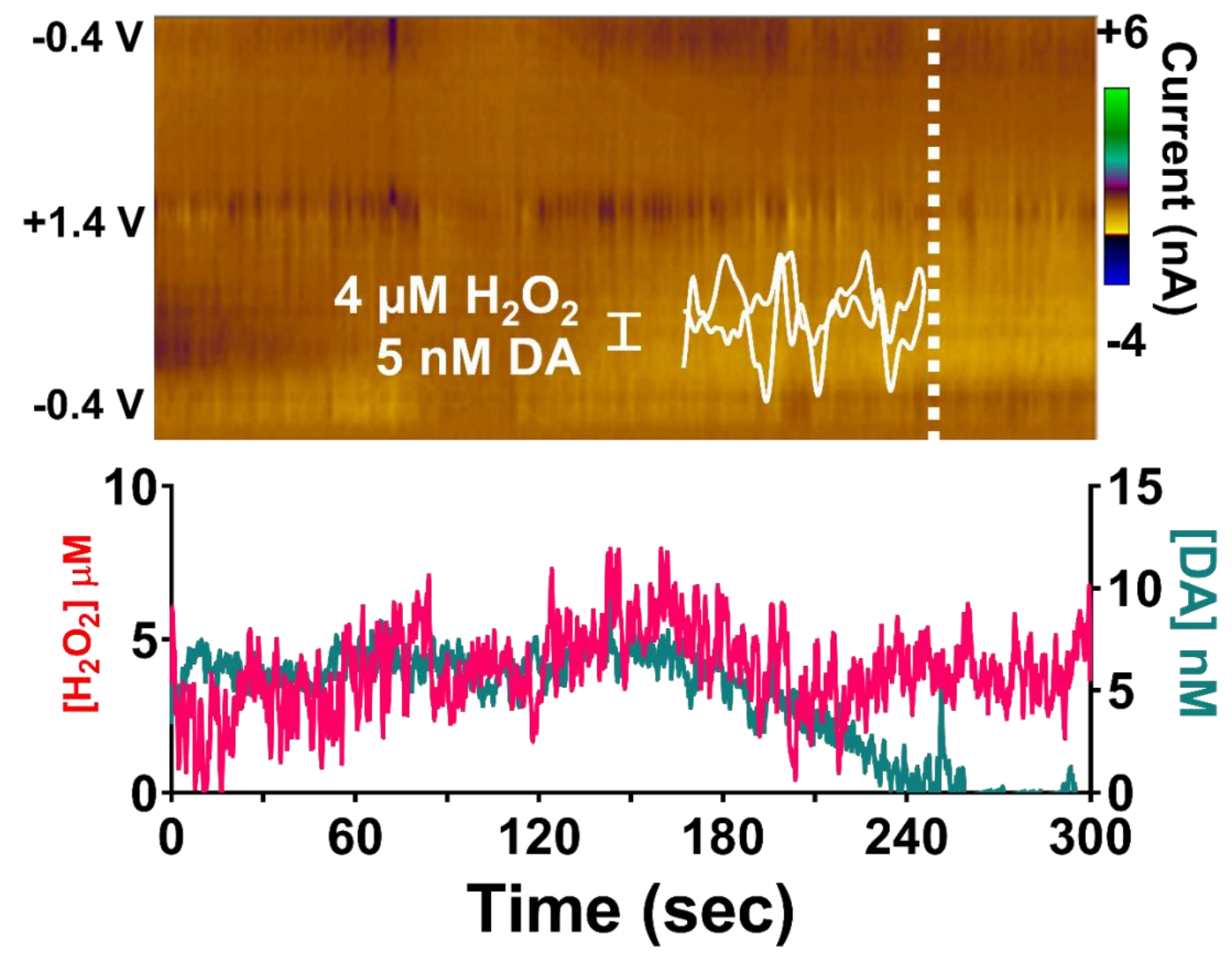

Figure S4: Baseline recordings taken prior to L-DOPA administration depict minimal DA or $\mathrm{H}_{2} \mathrm{O}_{2}$ tone. Top: Representative color plot of raw data collected in the lesioned striatum of a parkinsonian rat prior to L-DOPA administration. Minimal electrode drift is evident. Bottom: Baseline-normalized DA and $\mathrm{H}_{2} \mathrm{O}_{2}$ tone were stable. 


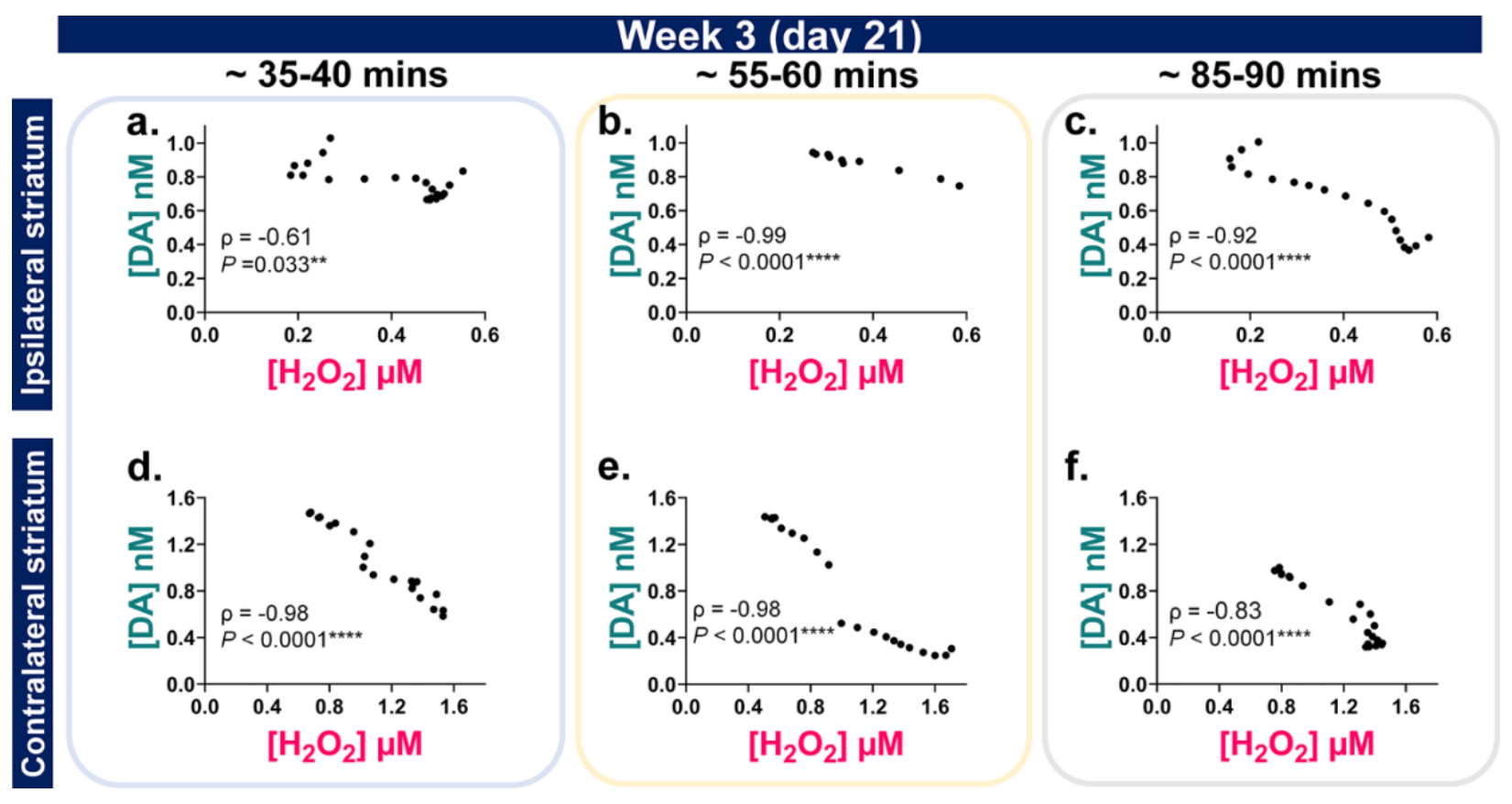

Figure S5: Spearman's nonparametric correlation plots for $\mathrm{DA}$ vs $\mathrm{H}_{2} \mathrm{O}_{2}$ during rotational bouts, collected after 3 weeks of L-DOPA treatment. 


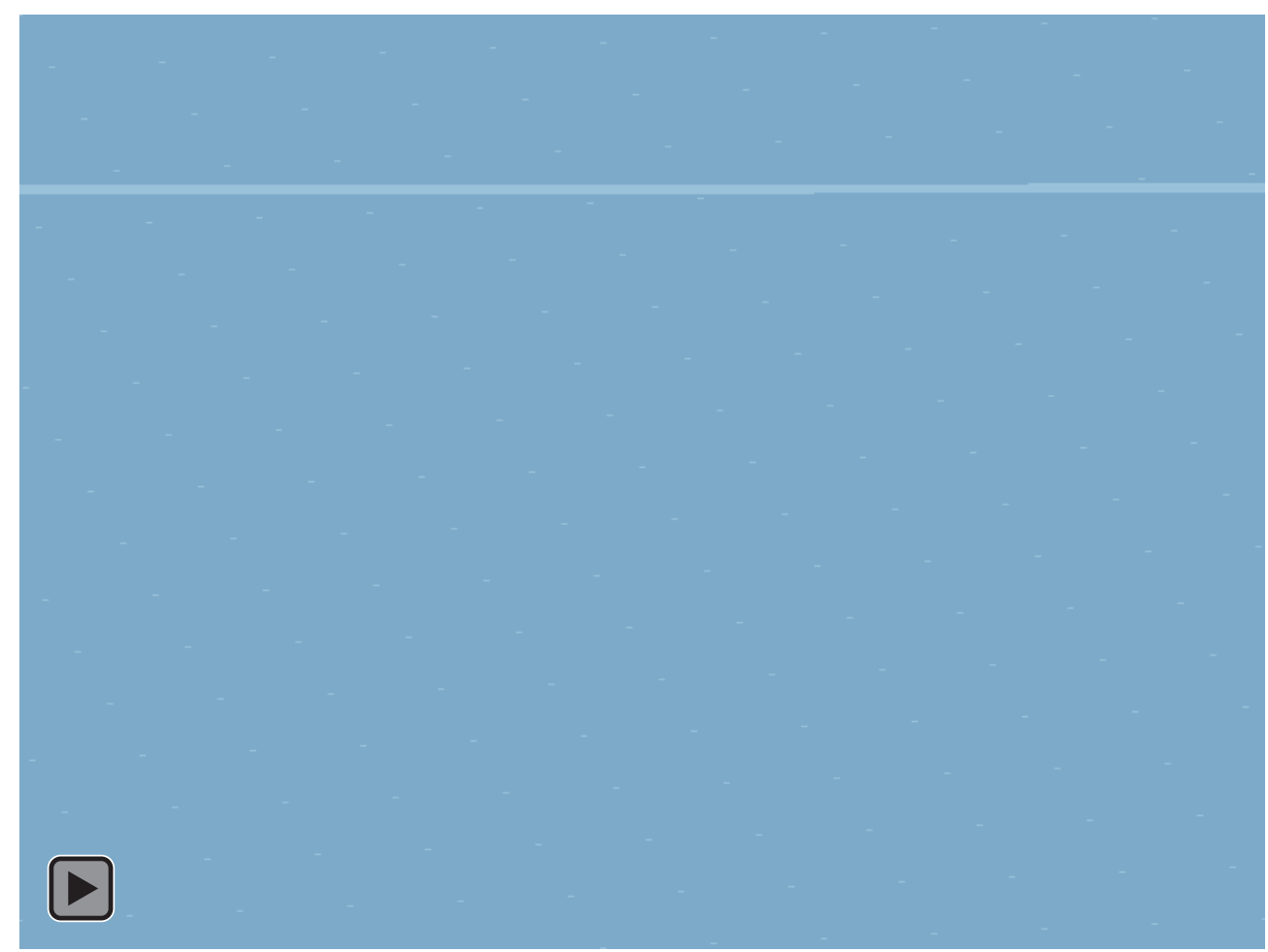

Video S1: Neurochemical dynamics in the striatum correlate with rotational behavior. Representative video of a hemiparkinsonian rat collected $\sim 60$ mins after L-DOPA administration, 3 weeks into treatment. $\mathrm{H}_{2} \mathrm{O}_{2}$ and DA dynamics in the ipsilateral striatum are negatively correlated at the onset of each rotational bout. 